\title{
Research Skills and Attitudes of Master Teachers in a Division towards Capability Training
}

\author{
Prof. Dr. Manolito Bada Basilio ${ }^{1}$ and Prof. Dr. David Cababaro Bueno ${ }^{2}$ \\ ${ }^{1}$ Graduate School Professor at Columban College, and Education Supervisor at the Department of Education, \\ Division of Zambales, Philippines \\ ${ }^{2}$ Dean of Graduate, and Colleges of Arts, Sciences and Education at Columban College, Inc., Olongapo City, \\ Zambales, Philippines
}

\begin{abstract}
The accurate assessment of research self-efficacy may help identify a given self-identified strengths and weaknesses with respect to research, thereby facilitating research training and guidance. This study focused on the Master Teachers' (MTs) skills and attitudes towards research as basis for research capability building program for MTs in the Schools Division of Zambales. The study used the descriptive-survey design. The data gathered were organized and processed through the SPSS. Majority of the MTs were middle aged, female and married, earned MA/MS units, and have served as Master Teacher I for 1-4 years. A very small percentage of the MTs have attended research-related trainings or conferences and undertaken, published or presented researches. They have average skills in searching, using and evaluating information including their awareness on the various sources of information and where to obtain them. They have fair skills in designing experimental study as well as selecting and developing research instruments, choosing appropriate statistical tools and preparing manuscript for publication. They strongly value training in educational research but moderately apply research findings to real life context. They have high regards relative to the value of doing research to become better educator. Time, efforts and resources in learning about research findings were essential elements to create positive attitudes towards research. A research capability training program is hereby proposed as the output of the study. The program consists of various levels from lectures, hands-on workshop, and writing research articles for colloquium and for possible publication.
\end{abstract}

Keywords: Education, master teacher, research skills and attitudes, capability program, Department of Education, descriptive-survey, Zambales

\section{Introduction}

The first academic revolution, taking off in the late 19th century, made research school's function in addition to the traditional task of teaching. At present, education is usually broken down into three components, namely teaching, research and service. Research is the systematic process of collecting and analyzing information to increase a human understanding of the phenomenon under study. In other words, research is a process comprised of data collection, analysis, interpretation, and assessment procedures conducted in a planned manner in order to find solutions to a problem. Teachers are the one who conduct research in school. Because of the education process and need to submit research for effective teaching, master teachers play an important role in research process.

During recent decades, the construct self-efficacy has been receiving growing attention in educational research. In summary, research self-efficacy refers to one's capabilities to execute particular tasks in research domain. Research self-efficacy has been found to predict students' interest in conducting research and is related to research productivity among students (Kahn, 2001). The accurate assessment of research self-efficacy may help identify a given self-identified strengths and weaknesses with respect to research, thereby facilitating research training and guidance. Research has shown that low research self-efficacy can interfere with research training and their willingness to conduct research (Love et al. 2007). Research has also shown that high research self-efficacy is an important factor related to successfully conducting research and pursuing research beyond graduate study (Forester et al. 2004). 
However, little is known about research self-efficacy and its correlates among Mater Teachers (MTs) particularly in the Division of Zambales. This knowledge enables us to better understand and minimize elements that could impede or interfere with the research process. Therefore, the goal of this research was to investigate the MTs personal and professional characteristics, research skills and attitude towards research.

The 1987 Philippine Constitution declares the policy of the State to "establish, maintain and support a complete, adequate, and integrated system of education relevant to the needs of the people, the country and society-at-large." A strong basic education is the key to this State policy. Teachers, then, play an integral role in ensuring that this policy is carried out. Cognizant of this, the government institutionalized mechanisms in order to "promote and improve the social and economic status of public school teachers, their living and working conditions, their terms of employment and career prospects in order that they may compare favorably with existing opportunities in other walks of life, attract and retain in the teaching profession more people with the proper qualifications" (Magna Carta for Public School Teachers).

One of these mechanisms is the introduction of Master Teacher positions in the Philippines, initially in 1978, at four levels, which match the salary grades of principals and assistant principals. With this, a two-track system of career progression for teachers was made available: school administration and classroom teachers. As in most countries, the career paths of teachers, especially talented practitioners lead to headship which is done by progressively reducing classroom work in order for them to take on leadership and management responsibilities (Bush, Glover, Yoon Mooi \& Romero, 2015). In order to maintain talented teachers in the classroom, some educational systems established a mechanism which offers alternative promoted posts, often described as master teachers (Bush et.al., 2015). This is also the case in the Philippines.

Master teachers are expected to have more experience in curriculum development, professional development, and mentoring than a traditional teacher; they serve as a role model for all other instructional staff and are considered the "gold standard" in teaching (NIET cited in Moore, 2015). They are considered the "crème de la crème" of the teaching profession and their teaching practices will be different from the general, non-master teachers. (Ibrahim, Aziz \& Nambiar, 2013).

McClean (2009) described MTs are as those who have superior preparation, exceptional teaching strategies, motivation and communication skills, sound curriculum knowledge, interpersonal competence, and classroom management proficiencies. Further, MTs are perceived as effective teachers, staff developers, stimuli of curriculum leadership and the strong provider of instructional leadership.

Given this important role of MTs in the educational system, they are in the best position to influence educational policies through research. The importance of educational research in the system needs no further emphasis. Livingstone (2005) of the UNESCO-International Institute for Educational Planning (IIEP) on Basic Elements of Research Design underscores that in an ideal world, educational research has a vital role to play in the improvement of education, whether this be in the development of theory to better explain why things occur the way they do in particular learning situations, or stimulating ideas for innovative practices, or developing new procedures and materials to enhance the efficiency and effectiveness of instruction. Moreover, educational research has the role of providing attested information to improve the quality of decision-making for educational policy.

The conduct of educational research especially in basic education is reinforced in Republic Act 9155 or the Governance of Basic Education Act of 2001 (Chapter 1, Section 7 (5), RA 9155) as it mandates Department of Education (Deped) to "undertake [national] educational research and studies" which can become part of the basis for necessary reforms and policy inputs. Deped Order 43, s. 2015 or Revised Guidelines for the Basic Education Research Fund (BERF) further emphasizes this as it called for evidence-based policy development through the institution of reforms that strengthen transparency and accountability (DepEd Order No. 43, s. 2015). On top of this policy, DepEd started to provide funding facility for research through the Basic Education Research Fund (BERF) under DepEd Order No. 24, s. 2010. The said fund was made available to internal and external research 
practitioners that meet the minimum eligibility requirements. To date, DepEd Order No. 43, s. 2015 revitalized this initiative with the revised guidelines for BERF.

In the regional level, DepEd Region 3 issued Regional Memorandum No. 144, s. 2015 which underscored the implementation of Rationalization Program of the Department as foreground for the conduct of policy and action researches across hierarchical levels and functional divisions. The Regional Office is mandated to formulate the regional research policies to ensure the unified direction in conducting policy and action researches.

The Region's goals of formulating research-based policies and strategies across disciplines to support the attainment of the direction of the Department of Education in general and the region in particular; developing professional communities of practitioners in various divisions equipped with scientific and creative thinking skills; and organizing academic gatherings as an avenue for exchange of research outputs - define the Regional Office's commitment of its contribution towards the attainment of DepEd Central Office's vision and mission through research.

These research directions bind Schools Divisions to implement research-related programs and projects of the DepEd Central and Regional Offices and formulate and initiate parallel ones that address specific problems in schools.

DepEd Zambales has framed its research initiatives anchored on the objectives of its Schools Division Education Development Plan (SDEDP) covering a period of six years, 2015-2020 setting out the research direction and priority areas for improvement identified within DepEd's three general thematic areas: ACCESS, QUALITY and GOVERNANCE. One of the objectives stated therein is, "To develop a culture of research in the Schools Division." The SDEDP objectives serve as take-off points for research to guide DepEd Zambales personnel especially the Master Teachers (MTs) who are mandated to do action researches.

These mechanisms manifest the full support of the government to educational research. This provides the perfect environment for Master Teachers to conduct action researches which can become bases for policy proposals and reforms. This is, in fact, part of the duties and responsibilities of MTs based on the Results-Based Performance Management System (RPMS) where it is stipulated under the Position and Competency Profile "conducts in-depth studies or action researches on instructional problems" and "conducts at least one action research every year".

However, in the Research Capability Training cum Colloquium for Master Teachers (MTs) conducted on September 2-4, 2015 by the Planning and Research Unit of DepEd Zambales, it was revealed that 70\% of some 300 MTs in the Schools Division have difficulty conceptualizing an action research proposal which they were required to submit prior to the training. Data gathered in this training served as baseline data besides a survey questionnaire that purports to identify and gauge their ability to conduct action research, methodology skills in particular.

It is upon this premise that this present study was initiated to identify the skills and attitudes of MTs towards conducting research. While the earlier discussion presented the mechanisms, in terms of policy, system and funding that provides an environment where MTs can readily conduct educational research, it is likewise important to look into internal factors such as research skills and attitudes to understand the difficulty being experienced by the MTs when it comes to conducting research. Thus, a thorough understanding into MTs attitudes towards research would also provide valuable input as to why only a few MTs conduct action researches considering that this is part of their mandate.

\section{Objective Of The Study}

The study aimed to analyzed the skills and attitudes of Master Teachers towards research, specifically action research which they are mandated to conduct as one of their duties and responsibilities as stated in the Results- 
Based Performance Management System- Position Competency Profile (RPMS-IPCRF) and Civil Service Form 1.

\section{Methodology}

This study utilized the descriptive-survey design in investigating the research skills and attitude of Master Teachers. This method is to describe systematically the facts and characteristics of a given population or area of interest, factually and accurately. The characteristics of descriptive research are accumulating a database to describe a situation, event or entity. The purpose of survey studies are to collect detailed factual information that describes existing phenomena; to identify problems or justify current conditions and practices; to make comparisons and evaluations; and to determine what others are doing with similar problems or situations and benefit from their experience in making future plans and decisions (Bueno, 2016).

The study utilized computer software namely sample size calculator in determining the sample size of 183 respondents from the population of the 346 Master teachers who are stationed in public elementary and secondary schools in the Division of Zambales They are chosen as participants since one of their duties and responsibilities is to conduct action research as stated in their Position and Competency Profile in the ResultsBased Performance Management System (Conducts in-depth studies or action researches on instructional problems and conducts at least one action research every year) and as further emphasized in their duties and responsibilities as reflected in their Position Description Form (Civil Service Commission Form 1).

The sampling design to be used is a non-probability sampling, specifically convenience sampling, which entails the use of the most readily, and conveniently available respondents as sample for the study. Convenience sampling is advantageous especially for pilot studies since it gives the researcher an initial idea about the trends and other basic information of the phenomenon being observed. Moreover, compared to other sampling techniques, it is cheaper, fast, and easy to conduct (Castillo, 2009). In the case of this current study, the most conveniently available Master Teachers from 13 District in Zambales composed of public elementary and secondary schools.

This study used survey questionnaire as main instrument used in data-gathering. The questionnaire that aims to measure research skills (information-seeking skills and methodology skills which are Likert-type with 26 and 13 items each respectively) was adapted from Meerah, et. al. (2011) while the questionnaire that purports to measure attitudes towards research with 29 Likert-type items categorized under eight (8) identified factors was adapted from Ozturk (2011). The instruments which the researcher used so as to gather the data needed was the Survey Questionnaire. Since the instruments were adapted from identified sources and the researcher was allowed to use them through an e-mailed request, there was supposedly not any need for validation as they were constructed and validated by the sources who hold Doctorate Degree, thus considered as authorities and experts in the field, added to the fact that they already have used the instrument in their studies and others' as well. Nevertheless, the researcher still asked the help of other local experts to carefully look into the questionnaires if they suit the intended participants of the study. After which, the questionnaires were finalized and administered.

The data gathered were organized and processed through the Statistical Package for Social Sciences (SPSS). As one of the rules followed in the use of the software, the formula of the statistical tools used were not reflected anymore since the computer did not follow the steps in the manual computation. The frequency and percentage distribution were used to describe the profile of the respondents. The weighted mean was used to assess the Master Teacher research skills and attitude towards educational research.

\section{Results And Discussion}

Majority of the MTs were middle aged, female and married, earned MA/MS units, and have served as Master Teacher I for 1-4 years. A very small percentage of them have attended research-related trainings or conferences and undertaken, published or presented researches. The MTs have average skills in searching, using and evaluating information including their awareness on the various sources of information and where to obtain 
them. They have fair skills in designing experimental study as well as selecting and developing research instruments, choosing appropriate statistical tools and preparing manuscript for publication. The MTs strongly value training in educational research but moderately apply research findings to real life context. They have high regards relative to the value of doing research to become better educator. Time, efforts and resources in learning about research findings were essential elements to create positive attitudes towards research.

Certain qualifications were set to become a Master Teacher in the Department of Education which includes academic qualifications, performance, teaching experience and leadership potential. In connection with the findings, the lowest age range is 29-34 which means that it takes more or less five years to reach Master Teacher level in order to meet these qualifications. The highest age range is 65-70 since the retirement age in the DepEd is set at 65 .

Demographic variables have generally been associated with research productivity. Age has been studied in numerous works, with conflicting results. Many studies about productivity have indicated that the relationship between publication and age is not linear, although the overall rate of publication generally declines with age (Finkelstein, Seal \& Schuster 1998; Teodorescu 2000). According to Over (1982), research productivity of academics slightly decreased with age. Bland and Berquist (1997) also observed that the average productivity of academic members drops with age but many senior academics remains active and that there is no significant evidence that age determines a drop in productivity. Teodorescu (2000) investigated faculty publication across 10 countries and discovered that age significantly influences research productivity in the United States. In a study using a random sampling of 228 colleges and universities in the United States, Kotrlik et al. (2001) found that age does not significantly affect research productivity.

Recent investigations into the relationship between teaching and research among graduate students suggest that teaching experiences may also impact graduate students' research skills while involvement in research has the potential to influence teaching skill development. Lyons, Fisher \& Thompson (2005) found that teachers in the graduate programs reported improvement in their research skills as a result of participation in their graduate teaching fellowship programs. As Steigelmeyer and Feldon (2009) explained, inquiry-based teaching methods and research share cognitive processes as "researchers-in-training must reflect carefully on their own experiences and knowledge to refine their understandings of events in a similar way that teachers using inquirybased methods must carefully analyze knowledge to scaffold students ' learning effectively".

Researchers have gained interest in further exploring the relationship between teaching and research and how each of these activities (as well as the integration of these activities) impact the development of graduate students' teaching and research skills (Deen \& Lucas, 2006; Maher, Timmerman, Hurst, \& Gilmore, 2009; Robertson \& Blackler, 2006; Steigelmeyer \& Feldon, 2009). However, one barrier to examining these relationships stems from the lack of validated instruments designed to capture each of these areas in tandem (teaching skills and research skills).

To promote education for all, many institutions of higher education are now proposing to introduce courses about reading and carrying out research studies as part of their regular program of instruction at undergraduate and graduate levels (Sanyal, 2005). The results reflect the inadequacy of capability trainings on research for majority of the respondents. While the importance of research in education and the teaching profession has been overly emphasized with the mechanisms such as policies and programs already in place, the reality, at this time, is that teachers and, in this case, Master Teachers are not capable of undertaking research due to lack of training. international research-related conferences.

These findings mirror that of the findings on the attendance of teachers in research trainings, i.e., majority have not attended research conferences from the school-level to the international-level. Productivity among MTs results from writing, reading, and publishing research reports in professional refereed journals, and displaying it on the web, or to making it known to the public through any other means. According to Creswell (1986), research productivity is the extent to which lecturers engage in their own research and publish scientific articles in refereed journals, conference proceedings, writing a book or a chapter, gathering and analyzing original 
evidence, working with postgraduate students on dissertations and class projects, obtaining research grants, carrying out editorial duties, obtaining patents and licenses, writing monographs, developing experimental designs, producing works of an artistic or a creative nature, engaging in public debates and commentaries. Schools primarily measure research productivity based on published works, externally funded grants, and the number of citations the published works received (Middaugh, 2001). The most common productivity measures look at publications that are submitted, accepted or published. The published works could be journal articles, books, book chapters, monographs, conference papers, and research proposals written to receive external and internal grants (Middaugh, 2001). Moreover, Uzun (2002) observed a sharp decline in the research productivity of academics in terms of the number of articles published in journals indexed in the Social Science Citation Index database. Aina and Mabawonku (1998) observed that the highest proportion of rejection out of the papers submitted to the Journal of Library, Archives and Information Science (JLAIS) for publication. While reporting on research productivity in developing countries, Arunachallam (1992), as cited by Nwagwu (2007), opined that there were countries whose scholarly works had dominated the developing countries with a $13 \%$ contribution to the publishing of 140,000 periodical titles listed in Ulrich's Periodicals Directory.

Few studies have been conducted examining important research skills of developing researchers; however, some work in this area is available. For example, Kardash (2000) developed an instrument designed to capture the developing research skills of undergraduates engaged in research, while Powers and Enright (1987) constructed a survey measuring graduate student research skills that were deemed important by faculty members.

Moreover, minimum evidence of attention directed on teaching faculty's perspective of information literacy coupled by a recurring theme in the literature on the importance of collaborative effort between faculty and librarians for the success of information literacy in higher education were two major motivations for this research into the beliefs and behavior of university academics in the promotion of information literacy at the University of the South Pacific (USP). The Statistical Anxiety Rating Scale (Cruise et al., 1985) was designed to measure the value of statistics, the interpretation of statistical information, test anxiety, cognitive skills in statistics, fear of approaching the instructor and fear of statistics. Other similar instruments included the Statistics Attitude Survey (Roberts \& Bilderback, 1980), and the Statistics Anxiety Inventory (Zeidner, 1991).

In order for teachers to remain effective over the years, they must keep up-to-date with constant changes in educational research, development and policy. There are frequent changes in curriculum, assessment modalities, and economic realities that affect the teaching and learning environment. Teachers have to keep pace with these new developments and trends or fall behind, lose their competitive edge and place their students at a disadvantage.

As in other professions, teachers must find the time to practice lifelong learning in their subject areas and pursue continuing professional development (CPD). They need to keep up-to-date with new pedagogical methods and best practices in their field. These measures are equally important for inexperienced and veteran teachers. Time does not stand still and students have differing needs. Teachers cannot continue to teach the same content in the same way, in every class, from year to year. The educational context keeps changing. In other words teachers must keep their subject knowledge, pedagogical skills and communication skills up-to-date on an ongoing basis.

There are many ways for teachers to keep their practice up-to-date. The internet is an invaluable tool in this respect. Enormous amounts of information on any subject are available online. So is the latest in professional development and communication skills. Educational technology is there for the taking and teachers can take full advantage of it. Read educational blogs, newsletters, access podcasts, follow webinars and relevant social media pages. There are also helpful e-books and audio books. Research mentors can be very helpful in helping to keep teachers up-to-date through research. Teachers should also join or form professional subject organizations and participate in departmental activities that promote excellence and best practices. Each teacher must read educational literature since they need to locate your practice within appropriate educational theory. Conferences, seminars, Edcamps, research, and projects also play a definite role in keeping teachers up-to-date. Short courses, 
upgrades of qualifications or professional training, where necessary, can also increase teacher readiness and effectiveness in doing research.

Teachers typically tend to view research-related courses with negative attitudes and feelings. These negative attitudes have been documented in numerous studies for a number of years in relation to courses in research, statistics and mathematics (Adams \& Holcomb, 1986; Elmore \& Vasu, 1980; Wise, 1985).

One of the main problems of these attitudes is that they have been found to serve as obstacles to learning (Wise, 1985; Waters, Martelli, Zakrajsek, \& Popovich, 1988). In turn, these negative attitudes have been found to be associated with poor performance in such courses (Elmore, \& Lewis, 1991; Woelke, 1991; Zeidner, 1991). Causal models, however, suggest that attitudes are actually mediators between past performance and future achievement (Meece, Wigfield, \& Eccles, 1990). Prior research studies have found that negative attitudes toward a course (mathematics) have been found to explain a significant portion of the variance in student learning (Ma, 1995). In turn, these attitudes influence the amount of effort one is willing to expend on learning a subject, which also influences the selection of more advanced courses in similar areas (research and statistics courses) beyond those of minimum requirements.

\section{Conclusions And Recommendations}

Majority of the MTs were middle aged, female and married, earned MA/MS units, and have served as Master Teacher I for 1-4 years. A very small percentage of them have attended research-related trainings or conferences and undertaken, published or presented researches. The MTs have average skills in searching, using and evaluating information including their awareness on the various sources of information and where to obtain them. They have fair skills in designing experimental study as well as selecting and developing research instruments, choosing appropriate statistical tools and preparing manuscript for publication. The MTs strongly value training in educational research but moderately apply research findings to real life context. They have high regards relative to the value of doing research to become better educator. Time, efforts and resources in learning about research findings were essential elements to create positive attitudes towards research. Thus, the MTs should continue upgrading their educational attainment by attending graduate and postgraduate education in the area of specialization, and by attending research-related conferences. The school authorities should consider reviewing incentive package for research-related activities of MTs to include training on research writing and publications. The MTs should acquire higher or advance skills searching and evaluating information as well as designing appropriate method, developing instruments, choosing appropriate statistical tools and preparing manuscript for publication. The MTs should improve their research attitudes related to classroom or schoolbased action research, applicability or usefulness of research findings to real life context, and reporting and publication of outputs. The research capability training program consisting of various levels from lectures, hands-on workshop, and writing research articles for colloquium and possible publication should be fully implemented immediately and regularly monitor its effectiveness.

\section{References}

[1] Adams, N. A., \& Holcomb, W. R. (1996).Analysis of the relationship between anxiety about mathematics and performance.Psychological Reports.

[2] Aina and Mabawonku (1998). Gender differences among physician scientists in self-assessed abilities to perform clinical research. Academic Medicine.

[3] Baltes, B., Hoffman-Kipp, P., Lynn, L., \& Weltzer-Ward, L. (2010). Students' research self-efficacy during online doctoral research courses. Contemporary Issues in Education Research.

https://doi.org/10.19030/cier.v3i3.187

[4] Bush, Glover, Yoon Mooi \& Romero (2015). Predicting research interest among rehabilitation counseling students and faculty. Rehabilitation Counseling Bulletin. 
[5] Bieschke, K. J. (2006). Research self-efficacy beliefs and research outcome expectations: implications for developing scientifically minded psychologists. Journal of Career Assessment.

https://doi.org/10.1177/1069072705281366

[6] Castillo, J.M. (2009). The utility of the research self-efficacy scale. Journal of Career Assessment.

[7] Creswell (1986). Applying social cognitive theory to interest in research among counseling psychology doctoral students: A path analysis. Journal of Counseling Psychology.

[8] Bland and Berquist (1997). Critical teaching skills present and absent in first year special education teachers. Paper presented at the meeting of Mid-South Educational :Research Association, November 19-21.

[9] Cruise et al., (1985). Statistical power analysis for the behavioral sciences. Hillsdale NJ: Earlbaum.

[10] DepEd Order No. 43, s. 2015 Revised Guidelines for the Basic Education Research Fund (BERF)

[11] Deen \& Lucas (2006). One man's heuristic is another man's blindfold. British journal of education. 3,179-183.

[12] Division Memorandum No. 56, s. 2015 Crafting the Schools Division Research Agenda for CY 2015-2020

[13] Elmore and Vasu (2080). Research groups as 'quasi-firms': the invention of the entrepreneurial university. Research Policy.

[14] Finkelstein, Seal \& Schuster (1998). Inquiry-based and problem-based Learning. Higher education and research development.

[15] Forester, M (2004). Factor structures of three measures of research selfefficacy. Journal of Career Assessment. https://doi.org/10.1177/1069072703257719

[16] Ibrahim, Aziz \& Nambiar (2013). Learning to solve complex problems in simulation. Higher education research and development.

[17] Kahn, J. H., \& Scott, N. A. (2001). Predictors of research productivity and science related career goals among counseling psychology graduate students. The Counseling Psychologist.

[18] Kardash (2000). An investigation into excellent tertiary teaching: Emphasizing reflective practice. http://www.springerlink.com/content/23u36x1850r5/

[19] Kotrlik et al. (2001). Factors changing attitudes of students toward an introductory research methodology course. Education.

[20] Lazo, Anito Jr., Labrador \& Prudente (2014). The views of undergraduate and postgraduate students, Studies in Higher Education.

[21] Love, K. M., Bahner, A. D., Jones, L. N., \& Nilson, J. E. (2007). An investigation of early research experience and research self-efficacy. Professional Psychology: -Research and Practice. https://doi.org/10.1037/0735-7028.38.3.314

[22] Mc. Clean, W. A. (2009). The master teacher: Role and responsibilities in the reform process. http://files.eric.ed.gov/fulltext/ED505868.pdf

[23] McGrath, E. (2002). Become more productive now. Available at: http://www.drdrew.com/Topics/article.asp?id=1039

[24] McMillan, J. \& Wergin, J. (2002). Understanding and evaluating educational research. New Jersey: Pearson Education.

[25] Meerah, T., (2011). Action research: Teachers as researchers in the classroom. Thousand Oaks, CA: Sage.

[26] Middaugh, M. (2001). Perceptions and attitudes toward research. Journal of Medical Imaging and Radiation Sciences, 47: 222-228.

[27] Moore, F. (2015). The role of research in developing teachers problems solving skills. Joumal of teacher education.

[28] Pajares, F., \& Urdan, T. (2006). Foreword. In F. Pajares, and T.Urdan (Eds.), Self-efficacy beliefs of adolescents.Greenwich, CT: Information Age Publishing. 
[29] Nwagwu, S. (2007). Influences on modelling preparation programs. Mid-South Educational Research Association, Louisville.

[30] Powers and Enright (1987). Research self-efficacy and productivity among students. The Counseling Psychology.

[31] Sanyal, L. (2005). Measuring the working advisor-advisee relationships in graduate school. Journal of Counseling Psychology.

[32] Steigelmeyer \& Feldon (2009). Teachers' attitudes towards research and productivity. International Journal of Qualitative Studies in Education.

[33] Waters, L. K., Martelli, T. A., Zakrajsek, T., \&Popovich, P. M. (1988). Attitudes toward statistics: An evaluation of multiple measures. Educational and Psychological Methods.

https://doi.org/10.1177/0013164488482026

[34] Woelke, 1991). Perceptual differences regarding the implementation of an inquiry-oriented student teaching curriculum. Journal of research and development in education

[35] Wise, W. F. (1985). Search for the excellent teacher and the emergence of the master teacher. Journal of Instructional Psychology

[36] Zeidner, 1991). Academic, Research, and Social Self-Efficacy among African American Pre-McNair Scholar Participants and African American Post-McNair Scholar Participants. Ph.D. Dissertation, Blacksburg, Virginia, USA 